\title{
Factors Associated with the Level of Depression among Elderly Women Residing in Old Age home of Devghat, Tanahu
}

\author{
Sirisa Gauli ${ }^{*}$ and Gauri Shrestha ${ }^{2}$ \\ Submitted: 04 June 2017; Accepted: 28 July 2017
}

\begin{abstract}
Background: There has been considerable increase in elderly population all over the world and this population is thought to be at a greater risk of depression which is a major health problem. Comparatively, depression is found to be at a higher rate among women compared to men.

Objective: This study aims to identify the factors influencing the level of depression among elderly women residing in old age home of Devghat, Tanahu.

Materials and Methods: This study is entirely based on primary data taking a total population (116) of elderly women from face to face interview using the short version of Geriatric Depression Scale (GDS), Instrumental Activities of Daily Living Scale (IADL) and socio-demographic interview schedule. To gather information, mobile data collection tool i.e. GIS Cloud was used. Data was analyzed using descriptive and inferential statistical methods. To determine the significant factors influencing depression among the respondents, multinomial logistic regression model was used.

Results: The mean score obtained from GDS was 7.52 ranging from 2 to 14 . About $24 \%$ of the respondents had mild depression and $47 \%$ of them had severe depression. More than $66 \%$ of them were from rural area. About $50 \%$ of respondents had no financial support; about $53 \%$ of them were found with feeling of loneliness. Regression analysis showed that the factors like age at marriage, type of place of previous residence, financial support, satisfaction of living condition, feeling of loneliness, and IADL score were found to be significantly associated with level of depression.

Conclusion: The result of the study indicates that most of the elderly women living in the old age home were suffering from depression. Some actions like raising fund through charity approach, counseling, promoting social volunteers or family members to visit old age home and supporting them, etc. should be addressed from the concerned authorities so that depression can be reduced which will support to the well-being and superior life of elderly women.
\end{abstract}

Keywords: Depression, elderly women, geriatric depression scale, instrumental activities to daily living scale, multinomial logistic regression, old age home.

Address correspondence to the authors: Central Department of Statistics, TU, Kirtipur, Nepal Email: sirisa.gauli@gmail.com ${ }^{1 *}$ (corresponding author email); gaurishrestha@ yahoo.com ${ }^{2}$ 


\section{INTRODUCTION}

Ageing is a natural phenomenon and an inevitable process. Every living being born, develops, grows old and dies. It is a process of gradual change in physical appearance and mental situation that cause a person to grow old. Different countries of the world term a man as an old after crossing certain age depending on prevailing socio-cultural norms and values. The United Nations has agreed that $60+$ years can be usually denoted as old age (WHO) and this is the first attempt at an international definition of old age. Besides, wrinkled face, grey hair, loosed teeth, weak condition of sense are other characteristics feature of old age (Bhandari, 2061). However, for its study of old age in Africa, the World Health Organization (WHO) set 50 years old as the beginning of old age. At the same time, the WHO recognized that the developing world often defines old age, not by years, but by new roles, loss of previous roles, or inability to make active contributions to society. The definitions of old age continue to change especially as life expectancy in developed countries has risen to beyond 80 years old. Whenever the people become old, they may be unproductive such that they cannot move their daily lives independently. If there is no one to care of them, they need a better place for their remaining lives. To overcome this problem different old age homes entitled with different naming are made in different places.

There are many old age homes in Nepal where the elderly people of ages 60 and above live the remaining days of their lives. Some of those elders are discarded by their sons/daughter because they are very old to be taken care of and some of those elders may not have children or relatives to live with. There is an Old Age Home in the premises of temple Pashupati Nath (Pashupati Bridrashram) for the destitute elders. Likewise in Devghat of Tanahun, Sitapaila of Kaski, Dhangadi, Kailali and many other places in different communities. One of the most popular places for old age home in Nepal is Devghat of Tanahu District in the Gandaki Zone of central Nepal. There are different old age homes in the area organised by different governmental and non-governmental organizations such as Devghat Area Development Committee Briddashram, NRN Briddashram, Rotary Karunalaya and Sri Galeshor Ashra.m Trust. Depression seems common in the elderly and is a major public health problem. World Health organization (WHO, 2005) also emphasizes that depression, which is the fourth most common illness, can lead to physical, emotional, social and economic problems. The prevalence rate of depression varies worldwide and their prevalence rates range between $10 \%$ and 55\% (Khattri and Nepal, 2006).

A study shows the depression ranges from $34.6 \%$ to $77.5 \%$ in old age home (Weyerer, Mann and Ames, 1995). A study conducted by Chalise (2014) has shown that there is higher prevalence among the elderly women residing in old age home of Devghat Dham. Also, the study conducted by 
Ghimire, Pokharel, Shyangwa, Baral, Aryal and Mishra (2012) found that Depression is more common among elders in old-age home than in community and it is more prevalent among elderly women than men. Another study by Sethi, Verma and Singh (2013) also found elderly subjects living in Old age home are more affected in terms of depression as compared to community dwelling elder subjects. Reason for higher prevalence might be that the institutionalized elderly feel lonelier and depressed as they lack social network support and do not feel "the level of kinship" felt by noninstitutionalized aged.

\section{MATERIALS AND METHODS}

\section{Data and study area}

This study is entirely based on the primary data collected by the researcher. The area of study is old age homes located in Devghat of Tanahu District of Nepal. There are four old age homes in this area named as Devghat Area Development Committee Briddashram, NRN Briddashram, Rotary Karunalaya and Sri Galeshor Ashram trust. All the elderly women residing in old age home of Devhat were considered as study population. All the elderly women living in these four residences were approached to include in this study. Elderly women who had been staying for at least six months were considered eligible. The women residing in the old age home who were absent at study time were excluded from study. Also, the women who were disabled to respond due to certain health problem were excluded. Out of 125 elderly women residing in old age home of Devghat, 116 were taken under study, 7 of them residing in Shree Galeshor Ashram Trust were absent at the time of survey and two of them residing in Rotary Karunalaya Briddashram were unable to respond due to certain health problem. All the elderly women under study responded to all the questions asked to them.

The study protocol was approved by the Head of Department of Statistics, TU, Kathmandu. A request letter for the permission of data collection was submitted to each institution of Devghat. Data for the study was collected using schedule regarding socio-demographic information prepared for the study from face to face interview. To measure the level of depression among the respondents under study Geriatric Depression Scale (GDS) was used which is a standard and comprehensive tool. GDS had 15 statements with yes or no response. For the interpretation of situation of depression, Sheikh and Yesavage (1986) have suggested score 0-4 as normal, 5-8 as mild depression, 9-15 as severe depression. All the information was gathered by one-to-one interview with the respondents by researcher own self. To measure the dependency of the respondents for their daily life Instrumental Activities to Daily Living Scale (IADL) was used. Functional Capability of elderly women was measured using eight items. To calculate the level of functional capability the sum of the above eight 
items was added and measured as a continuous variable. Higher the value of IADL score indicates the lower the dependency. All the information was gathered using mobile data collection application; GIS Cloud. To ensure the questionnaire's quality and sensitivity Geriatric Depression Scale Short Form (GDSSF) and Instrumental Activities to Daily Living Scale (IADL) were translated into Nepali from English and then back translated into English language.

\section{Study variables}

In this study, level of depression was taken as dependent variable and measured using the short version of Geriatric Depression Scale (GDS). Reliability of GDS was measured through Cronbach's alpha (0.862) shows quite high in this study. And different socio-demographic variables like age, age of husband, region of previous residence, type of place of residence, religion, ethnicity, spousal status, age at first marriage, literacy status, family type, family size, number of son/daughter, monthly income, financial support from external source, allowance, source of income, previous income, occupation of husband, feeling of loneliness, health problem, type of health problem, regular health check- up, currently using medicine related to depression, psycho-social support, reason for living home, satisfaction of living condition, interest of returning to home were taken as independent variables.

\section{Statistical methods}

The data were analyzed by using the descriptive and inferential statistical methods. The descriptive analysis was done using various statistical measures like mean, median, standard deviation, maximum, minimum, chi-square test etc. To determine the significant factors influencing depression among the respondents which is ordinal in nature, ordinal logit regression model was used but the assumption of test of parallel lines in ordinal regression model was violated. Then multinomial logit regression model was used and interpreted.

\section{RESULTS}

The level of depression among the elderly women residing in old age home is given in Table 1. And the corresponding pie chart is shown in Fig. 1. For the measurements of depression GDS $(\mathrm{SF}=15)$ was used. This study found mean depression score of elderly women under study was 7.52 $( \pm 3.89)$ ranging from 2 to 14 . Level of depression is measured on the basis of depression score. This study shows that $32.8 \%$ respondents were normal, $24.1 \%$ had mild depression and $43.1 \%$ had severe depression. From this data we can say that prevalence of depression was $75.9 \%$ in this population. For the further regression analysis depression score was then categorized into three groups having score 0 - 4 as no depression, 5-8 as mild depression and 9-15 as severe depression. 
Table 1. Level of depression among elderly women residing in old age home, $\mathrm{N}=116$.

\begin{tabular}{|c|c|c|c|c|c|}
\hline Variables & $\mathrm{N}$ & $\%$ & Mean & SD & Range \\
\hline GDS score & 116 & $100 \%$ & 7.52 & 3.89 & $2-14$ \\
\hline \multicolumn{6}{|l|}{ Level of Depression } \\
\hline Normal (No Depression) & 38 & 32.8 & & & \\
\hline Mild Depression & 28 & 24.1 & & & \\
\hline Severe Depression & 50 & 43.1 & & & \\
\hline Total & 116 & 100 & & & \\
\hline
\end{tabular}

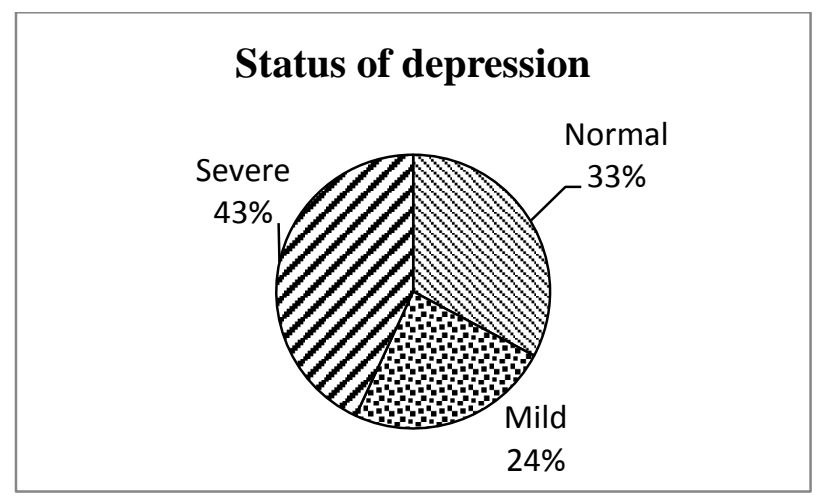

Fig. 1. Status of depression.

Table 2 shows that the distribution of socio- demographic and health related characteristics of the respondents included in this study. Out of 116 elderly women under study, only about $17 \%$ were residing in Rotary Krunalaya Briddashram, the age of the respondents ranged from 60 to 112 years with a mean $( \pm \mathrm{SD})$ age of $78.17( \pm 9.25)$ years, mean age at first marriage of the respondents was 11.12 ( \pm 3.13 ) ranging from 5 to 25 years, about $72 \%$ were from Hill region, about $34 \%$ of them were from urban area, about $77 \%$ of them were from Brahmin, more than three fourth of the elderly women were widowed, more than $84 \%$ of them were illiterate, about $54 \%$ of the respondents under study were seen to have no any financial support from others, about $53 \%$ of them were found having feeling of loneliness, about $77 \%$ of them had health problem, about $49 \%$ of the respondents were not satisfied with their living condition in old age home, mean value of IADL score of the respondents was found to be $4.16( \pm 2.57)$ ranging from 0 to 8 . 
Table 2. Selected background characteristics of elderly women under study, N=116.

\begin{tabular}{lll}
\hline \multicolumn{1}{c}{ Variables } & $\mathrm{N}$ & $\%$ \\
\hline Name of old age home & 20 & 17.2 \\
\hline Rotary Karunalaya & 28 & 24.1 \\
\hline NRN Briddashram & 26 & 22.4 \\
\hline Devghat Area Development Committee & 42 & 36.2 \\
\hline Galeshor Ashram & & \\
\hline Region of previous residence & 1 & 0.9 \\
\hline Mountain & 83 & 71.6 \\
\hline Hill & 32 & 27.6 \\
\hline Terai & 40 & 34.5 \\
\hline Place of previous residence (Urban) & 90 & 77.6 \\
\hline Ethnicity (Brahmin) & 86 & 74.1 \\
\hline Spousal status (Widowed) & 98 & 84.5 \\
\hline Literacy status (Illiterate) & 63 & 54.3 \\
\hline Financial support from external source (No) & 62 & 53.4 \\
\hline Feeling of loneliness (Yes) & 89 & 76.7 \\
\hline Health problem (Yes) & 57 & 49.1 \\
\hline Satisfaction of living condition (No) & & \\
\hline
\end{tabular}

From the comparison of level of depression among the respondents with other related variables separately, Payments Status of old age home $(P=0.02)$, Age $(P<0.001)$, Age at marriage $(P=0.109)$, Having son/daughter $(P=0.073)$, Financial support from external source $(P<0.001)$, Feeling of Loneliness $(P=0.011)$, psycho-social support $(P=0.001)$, Satisfaction of living condition $(P<0.001)$, IADL $(P<0.001)$ were significantly associated with the level of depression at $10 \%$ level of significance and were included in the logistic regression analysis, non-significant predictors were removed from the final fitted model. Out of the total respondents, 10 respondents were seen to be currently using medicine related to depression and only two of them were seen not having depression. So in the fitted model, these two respondents were excluded and the final sample size for the model is 114. Taking the level of depression having three categories viz. normal (no depression), mild and severe which is ordinal in nature as dependent variable and above listed variables as independent variables, ordinal logistic regression model had been tried to fit. But due to the violation of assumption of parallel lines in ordinal regression model, an alternative model called multinomial 
logistic regression was adopted. Taking level of depression as dependent variable and above listed variables as independent variables, the model was run.

Table 3 contains the estimates of multinomial logistic regression coefficients, their $p$ values and odd ratios for each category. From the fitted multinomial logistic regression, the factors like age at marriage, IADL, type of place of previous residence, financial support from external source, satisfaction of living condition and feeling of loneliness are found to be significant to the level of depression of elderly women residing in old age home of Devghat. From the Table 3, the factors like age at marriage $(\mathrm{OR}=0.747,95 \% \mathrm{CI} 0.575-0.969, P=0.028)$, IADL (OR=0.497, 95\% CI 0.341-0.726, $P<0.001)$, type of place of residence ( $\mathrm{OR}=0.242$, 95\% CI $0.054-1.080, P=0.063)$ are seen to be significant for explaining mild depression relative to normal at $10 \%$ level of significance whereas the factors like IADL ( $\mathrm{OR}=0.292,95 \%$ CI $0.181-0.471, P<0.001$ ), financial support from external source $(\mathrm{OR}=23.142,95 \% \mathrm{CI} 3.377-158.575, P=0.001)$, satisfaction of living condition $(\mathrm{OR}=20.006,95 \% \mathrm{CI}$ 3.13-127.510, $P=0.002)$, feeling of loneliness ( $\mathrm{OR}=0.132,95 \% \mathrm{CI} 0.026-0.677, P=0.015)$ are found to be significant for explaining severe depression relative to normal at $5 \%$ level of significance.

The odds ratio of age at marriage for mild depression relative to normal is seen to be 0.747 which means that the odds of having mild depression relative to normal among the women who got married one year later is $26 \%$ less as compared to that among those married one year earlier. In other words the women who got married in later age have less chance of having mild depression. But it does not show the significant effect on the level of depression by normal versus severe depression. The odds ratio of IADL for mild depression relative to normal is seen to be 0.497 which reveals that the odds of having mild depression relative to normal among the women having one more IADL score is 52\% less as compared to that among those having one unit less IADL score. Similarly, the odds of having depression level by normal versus severe depression is $71 \%$ less likely for IADL with one more score as compared to those having one less score. The odds ratio of type of place of previous residence for mild depression relative to normal is 0.242 which indicates that the women form rural area are $76 \%$ less likely to have mild depression relative to normal as compared to those from urban area. But it does not show the significant association for depression level by normal versus severe depression. Next, financial support does not show the significant effect on level of depression by normal versus mild depression. However, it has strong and significant effect on level of depression by normal versus severe depression. The odds ratio of financial support for severe depression relative to normal is seen to be 23.142 which mean that the women having no any financial support are 23 times likely to have severe depression relative to normal compared to those having financial support. 
Table 3. Fitted model for explaining the level of depression, $N=114$.

\begin{tabular}{|c|c|c|c|c|c|c|c|}
\hline \multirow{3}{*}{ Depression } & \multirow{3}{*}{ Variables } & \multirow{3}{*}{ B } & \multirow{3}{*}{$\begin{array}{l}\text { Std. } \\
\text { Error }\end{array}$} & \multirow{3}{*}{$p$-value } & \multirow{3}{*}{ OR } & \multicolumn{2}{|c|}{$95 \% \mathrm{CI}$ for OR } \\
\hline & & & & & & Lower & \\
\hline & & & & & & Bound & Bound \\
\hline \multirow{7}{*}{ Mild } & Intercept & 7.699 & 2.075 & $<0.001^{* * *}$ & & & \\
\hline & Age at Marriage & -0.292 & 0.133 & $0.028^{* *}$ & 0.747 & 0.575 & 0.969 \\
\hline & IADL & -0.698 & 0.193 & $<0.001^{* * *}$ & 0.497 & 0.341 & 0.726 \\
\hline & $\begin{array}{l}\text { Type of place of } \\
\text { residence Rural } \\
\left.\text { (Urban }{ }^{\circledR}\right)\end{array}$ & -1.417 & 0.762 & $0.063^{*}$ & 0.242 & 0.054 & 1.080 \\
\hline & $\begin{array}{l}\text { Financial support from } \\
\text { external source =No } \\
\left(\text { Yes }{ }^{\circledR}\right)\end{array}$ & 0.722 & 0.771 & 0.349 & 2.059 & 0.455 & 9.327 \\
\hline & $\begin{array}{l}\text { satisfaction of living } \\
\text { condition=No } \\
\left(\text { Yes }{ }^{\circledR}\right)\end{array}$ & 0.369 & 0.760 & 0.627 & 1.447 & 0.326 & 6.421 \\
\hline & $\begin{array}{l}\text { feeling of loneliness=No } \\
\left.\text { (Yes }{ }^{\circledR}\right)\end{array}$ & -0.970 & 0.680 & 0.154 & 0.379 & 0.100 & 1.439 \\
\hline \multirow{7}{*}{ Severe } & Intercept & 4.750 & 2.157 & $0.028^{* *}$ & & & \\
\hline & Age at Marriage & -0.090 & 0.118 & 0.447 & 0.914 & 0.726 & 1.152 \\
\hline & IADL & -1.232 & 0.245 & $<0.001^{* * * *}$ & 0.292 & 0.181 & 0.471 \\
\hline & $\begin{array}{l}\text { Type of place of } \\
\text { residence=Rural } \\
\text { (Urban }{ }^{\circledR} \text { ) }\end{array}$ & -0.555 & 1.035 & 0.592 & 0.574 & 0.075 & 4.366 \\
\hline & $\begin{array}{l}\text { Financial support from } \\
\text { external source =No } \\
(\text { Yes } ®)\end{array}$ & 3.142 & 0.982 & $0.001^{* * *}$ & 23.142 & 3.377 & 158.575 \\
\hline & $\begin{array}{l}\text { satisfaction of living } \\
\text { condition=No } \\
\text { (Yes } 囚)\end{array}$ & 2.996 & 0.945 & $0.002^{* *}$ & 20.006 & 3.139 & 127.510 \\
\hline & $\begin{array}{l}\text { Feeling of loneliness }=\text { No } \\
\left.\text { (Yes }{ }^{\circledR}\right)\end{array}$ & -2.023 & 0.833 & $0.015^{* *}$ & 0.132 & 0.026 & 0.677 \\
\hline
\end{tabular}

$\mathrm{OR}=$ odds ratio, ${ }^{\circledR}=$ reference category, $*=$ significant at $10 \%$ level of significance, $* *=$ significant at $5 \%$ level of significance, $* * *=$ significant at $1 \%$ level of significance 
Similarly, the satisfaction of living condition does not show the significant impact on depression level by normal versus mild. However, it is significant for severe depression relative to normal. The odds ratio of satisfaction of living condition for severe depression relative to normal is seen to be 20.006 which indicate that the women having no satisfaction of living condition are 20 times likely to have severe depression relative to normal as compared to those who satisfied with their living condition. Furthermore, feeling of loneliness is another predictor of level of depression. It does not show the significant influence on the depression level by normal versus mild at $5 \%$ level of significance. However, it has strong and significant impact on level of depression by normal versus severe depression. The odds ratio of feeling of loneliness for severe depression relative to normal is seen to be 0.132 which reveals that the women not having feeling of loneliness are $87 \%$ less likely to have severe depression relative to normal as compared to those having feeling of loneliness.

\section{Model adequacy test}

To see the degree of explanation by the covariates used in the fitted model on variation in level of depression, pseudo $R^{2}$ are calculated. Here Negelkerke's $R^{2}$ was found to be 0.741 which indicates that $74.1 \%$ of the variation in depression level has been explained by the independent variables. Similarly, to examine the overall goodness of fit of the model, Hosmer and Lemeshow statistic for two different categories is used. Here, Hosmer and Lemeshow test for mild depression relative to normal showed chi-square value as 3.416 with $p$ value $=0.906$. Similarly, Hosmer and Lemeshow test for severe depression relative to normal showed chi-square value as 2.2085 with $p$ value $=0.948$. It shows that there is no such significant difference in observed and expected number for both of the groups viz. normal and mild depression and normal and severe depression.. Also, the $p$-value for calculated chi-square is more than 0.05 in both cases which indicates that the fitted model is good for explaining the level of depression among the women under study.

\section{DISCUSSION}

Present study conducted with an objective to assess the level of depression and its associated factors found that the prevalence of depression measured through GDS (SF = 15) among Briddashram living Nepalese elderly women was $75.9 \%$. Among them about 32\% respondents were normal, $24.1 \%$ had mild depression and maximum of them (43.1\%) had severe depression. This study found mean depression score of elderly was $7.52( \pm 3.89)$ ranging from 2 to 14 . A similar kind of study done by Hom Nath Chalise in Nepal observed that the prevalence of depression was 57.8\%. Among them $46.7 \%$ had mild, $8.9 \%$ had moderate and $2.2 \%$ had severe depression, mean depression score of elderly was $5.6( \pm 2.19)$ ranging from 3 to 13 . From the findings of this study, it can be concluded that the factors like age at marriage, type of place of previous residence, financial support from external 
source, satisfaction of living condition feeling of loneliness and IADL score was found to have significant impact on level of depression among the elderly women residing in old age home of Devghat, Tanahu.

The result of the study has been supported by various studies in the world. Impaired in instrumental activities of daily living (IADL) is an expression of functional dependence and one of the most commonly used measures in assessing health in old age. This study found having functional disabilities assessed by IADLs as an important predictor of depression. This finding is consistent with many other studies across the world (Chalise, 2014, Imran, Azidah, Asrenee and Rosediani, 2009; Biderman, Cwikel, Fried and Galinsky, 2002 and Penninx, Guralnik, Ferrucci, Simon- sick, Deeg and Wallace, 1998). Loneliness was also another predictor of depression in the elderly women living in old age home. This finding is also consistent with previous studies from Nepal showing loneliness is quite high among Nepalese woman elderly compared to male (Chalise, et al., 2007) and loneliness was found significantly correlated with depression in this study (Chalise, 2014). A study carried out by Singh and Mishra (2009) also found a significant relationship between loneliness and depression. Mohan and Begum (2011) also found positive correlation between depression and loneliness. Two studies conducted by Maulik and Dasgupta (2012) and Malhotra et al. (2010) have supported the result of the study showing significant association of financial support and level of depression. Some of the important variables seen to be highly associated with depression in previous studies like age, ethnicity, previous family type, psychological support, physical illness, length of stay, etc. are found to be insignificant in this study. Behind this result, one reason may be the use of different tools form measuring depression and sincerity of responding by the respondents

\section{CONCLUSION}

Prevalence of depression is found considerably high and the factors like IADL, financial support from external source, satisfaction of living condition, age at marriage and type of place of previous residence are significantly associated with level of depression among the women residing in old age home of Devghat, Tanahu. The findings of this study suggest that level of depression is a serious problem among Nepalese elderly women residing in Devghat area which is considered a hallowed place for Hindus. Further researches are also needed to identify risk factors of increasing depression among the elderly women in Nepal. This may contribute to the authorization of the elderly women and, thus, improve their quality of life in the future. Similarly, the women who are dependent on others for their daily life are seen having more depression level, they should be helped properly for their daily life. The related family members and authorities should provide strong financial support to the women residing in old age home to decrease the prevalence of depression among them. On the 
other hand, social appeal to support old age and develop fund raising through charity approach may be helpful. The implication in old age home management to promote healthy living within the premises by assessment of physical conditions and rectification process put in place, appealing external support organizations - individually and organization base, promotion of social volunteers or family members visit to old age home and supporting them, doing things small but meaningful such as music playing, regularization of group interactions can be other low cost approaches, etc. may be useful approaches to reduce high level depression among the women residing in old age home.

\section{CONFLICT OF INTEREST}

The authors declared that there is no conflict of interest.

\section{ACKNOWLEDGEMENTS}

Authors would like to express sincere gratitude to all those who provided support to complete this work and thank Prof. Dr. Shankar Prasad Khanal, Head of Central Department of Statistics, TU and Prof. Dr. Srijan Lal Shrestha for insightful comments and encouragement during the course of the study. Mr. Amrit Subedi should also be thanked for his involvement during the study period.

\section{REFERENCES}

Ministry of Women, Children and Social Welfare. (2061). Empowerment of Elder. Kathmandu Nepal: Bhandari, R.R.

Biderman, A., Cwikel, J., Fried, A.V., \& Galinsky, D. (2002). Depression and falls among community dwelling elderly people: A search for common risk factors. Journal of Epidemiology \& Community Health, 56, 631-636. http://dx.doi.org/10.1136/jech.56.8.631

Chalise, H.N., (2014). Depression among elderly living in Briddashram (old age home). Advances in Aging Research, 3(1), 6-11.

Chalise, H.N., Saito, T., Takahashi, M., \& Kai, I. (2007). Relationship specialization amongst sources and receivers of social support and its correlations with loneliness and subjective well-being: A cross-sectional study of Nepalese older adults. Archives of Gerontology and Geriatrics, 44, 299-314. http://dx.doi.org/10.1016/

Ghimire, H., Pokharel, P. K., Shyangwa, P. M., Baral, D. D., Aryal, A. , \& Mishra, A. K. (2012). Are elderly people living in old-age home, less depressed than those of community? Findings from a comparative study. Journal of Chitwan Medical College, 1(2), 5-8.

Imran, A., Azidah, A.K., Asrenee, A.R., \& Rosediani, M. (2009). Prevalence of depression and its associated factors among elderly patients in outpatient clinic of university sains Malaysia Hospital. Medical Journal of Malaysia, 64, 134-139. 
Khatri, J.B., \& Nepal, M.K. (2006). Study of depression among geriatric population in Nepal, Nepal Med Coll Journal. 8(4), 220-3.

Lawton, M.P. \& Brody, E.M. (1969). Assessment of older people: Self-maintaining and instrumental activities of daily living. Gerontologist, 9, 179-186. http://dx.doi.org/10.1093/geront/9.3_Part_1.179

Malhotra, R., Chan, A., \& Õstbye, J. (2010). Prevalence and correlates of clinically significant depressive symptoms among elderly people in Srilanka: Finding from a national survey. Int Psychogeriatrics. 22(2), 227-236.

Maulik, S., \& Dasgupta, A. (2012). Depression and its determinants in the rural elderly of West Bengal-a cross sectional study. International J of Biomedical and Medical Research. 3(1), 1299-1302.

Mohanth, N., \& Begum, F.A. (2011). Geriateric depression, loneliness and psychological well-being: Roll of age and gender. Indian Journal of Psychology and Mental Health, 5, 53-61.

Penninx, B.W.J.H., Guralnik, J.M., Ferrucci, L., Simon- sick, E.M., Deeg, D.J.H., \& Wallace, R.B. (1998). Depressive symptoms and physical decline in community- dwelling older persons. The Journal of the American Medical Association, 279, 1720-1726. http://dx.doi.org/10.1001/jama.279.21.1720

Sethi, V., Verma, V., \& Singh, U. (2013). Impact of ageing on depression and activities of daily livings in normal elderly subjects living in old age homes and communities of Kanpur, U.P., International Journal of Medical Research \& Health Sciences, 2, 243-249. http://dx.doi.org/10.5958/j.2319-5886.2.2.028.

Sheikh, J.I., \& Yesavage, J.A. (1986). Geriatric Depression Scale (GDS): Recent evidence and development of a shorter version. Clinical Gerontology, 5, 165-173.

Singh, A., \& Misra, N. (2009). Loneliness, depression and sociability in old age. Industrial Psychiatry Journal, 18, 51-55. http://dx.doi.org/10.4103/0972-6748.57861

Weyerer, S., Mann, A.H., \& Ames, D. (1995). Prevalence of depression and dementia in residents of old age homes in Mannheim and Camden (London). Zeitschrift für Gerontologie and Geriatrie, 28, 169-178.

Reference to this paper should be made as follows:

Gauli, S., \& Shrestha, G. (2017). Factors associated with the level of depression among elderly women residing in old age home of Devghat, Tanahu. Nep. J. Stat., 1, 29-40. 